\title{
DIRETRIZES PARA MELHORAR A INTEGRAÇÃO DO PROJETO E DA PRODUÇÃO DE EMPREENDIMENTOS DA CONSTRUÇÃO CIVIL POR MEIO DO SISTEMA LAST PLANNER®
}

\author{
Bruno A. Bragato*, Ariovaldo D. Granja.
}

\section{Resumo}

Uma característica de empreendimentos complexos do setor da construção é a recorrente desconexão entre o processo de projeto e a produção da obra, em virtude da falta de transparência e comunicação entre ambos. Neste sentido, o presente trabalho teve como objetivo propor melhorias na integração entre o processo de projeto e da produção (IPPP) em obras na construção civil, por meio da utilização do Sistema Last Planner (SLP), além de identificar barreiras e oportunidades para sua implementação.

\section{Palavras-chave:}

Sistema Last Planner, lean construction, interface entre processo de projeto e de construção.

\section{Introdução}

Diversos autores, dentre eles Mitchell et al. (2011), apontaram a falta de integração entre projeto e produção, bem como a necessidade de estudo e análise da IPPP, suas características e a problemática envolvida nessa interface, almejando abordar o processo de projeto e de produção de maneira conjunta. Segundo Arrotéia (2014), foram realizadas poucas pesquisas acadêmicas relacionadas com a interface projeto-obra. Em vista desta lacuna, o presente trabalho objetiva determinar diretrizes que visem melhorar a integração entre o processo de projeto e a produção por meio da utilização do SLP, além de identificar oportunidades e barreiras para implantação destas diretrizes. Para este fim foram realizados três estudos de caso em empresas do setor, sendo dois destes em empresas com sistemas de produção do tipo engineerto-order (ETO).

\section{Resultados e Discussão}

Com base nos três estudos de caso realizados foi possível propor diretrizes para a integração entre o processo de projeto e de produção por meio do SLP. Tais diretrizes são apresentadas a seguir, podendo ser divididas nas seguintes etapas:
a) Diagnóstico
a1) compreensão da IPPP;
a2) identificação de Gargalos.
b) Implementação do SLP no planejamento de curto prazo na IPPP

b1) definição de reuniões semanais entre equipe responsável pelo projeto e pela produção;

b2) definição da prioridade de execução dos projetos de acordo com a necessidade e restrições da fábrica, porém, buscando um nivelamento entre o processo de projeto e de fabricação;

b3) definição dos projetos realizados na semana seguinte e dos pacotes de trabalho relacionados à fabricação no mesmo período;

b4) determinação no final da semana do PPC e das

causas de não conclusão das atividades;

c) Implementação do SLP no planejamento de médio prazo

c1) identificação e remoção das restrições das atividades de fabricação a fim de que elas possam ser planejadas no horizonte de curto prazo
Tabela 1. Oportunidades e barreiras identificadas para implementação das diretrizes.

\begin{tabular}{|c|c|c|}
\hline Diretriz & Oportunidades & Barreiras \\
\hline a)Diagnóstico & $\begin{array}{l}\text { Aprimorar a compreensão } \\
\text { acerca dos fluxos dos } \\
\text { projetos para equipe de } \\
\text { produção; identificar } \\
\text { oportunidades de } \\
\text { melhoria }\end{array}$ & $\begin{array}{l}\text { Resistência de } \\
\text { colaboradores } \\
\text { em implementar } \\
\text { mudanças }\end{array}$ \\
\hline $\begin{array}{l}\text { b)Implementaç } \\
\text { ão do SLP no } \\
\text { planejamento } \\
\text { de curto prazo } \\
\text { na IPPP }\end{array}$ & $\begin{array}{l}\text { Aprimorar integração } \\
\text { entre equipe responsável } \\
\text { pelo projeto e pela } \\
\text { produção; nivelamento } \\
\text { entre etapa de projeto e } \\
\text { de produção diminuindo } \\
\text { gargalos e obtendo um } \\
\text { fluxo mais contínuo; } \\
\text { controle e aprendizagem }\end{array}$ & $\begin{array}{l}\text { Alta variabilidade } \\
\text { de projetos e } \\
\text { oscilações de } \\
\text { demanda podem } \\
\text { dificultar o } \\
\text { nivelamento } \\
\text { entre projeto e } \\
\text { produção }\end{array}$ \\
\hline $\begin{array}{l}\text { c) Implementaç } \\
\text { ão do SLP no } \\
\text { planejamento } \\
\text { de médio prazo }\end{array}$ & $\begin{array}{l}\text { Remoção de restrições } \\
\text { das atividades que serão } \\
\text { planejadas no curto } \\
\text { prazo, aumentando } \\
\text { confiabilidade do } \\
\text { planejamento de curto } \\
\text { prazo }\end{array}$ & $\begin{array}{l}\text { Incerteza e } \\
\text { oscilação da } \\
\text { demanda do } \\
\text { mercado } \\
\text { diminuem a } \\
\text { confiabilidade } \\
\text { acerca do } \\
\text { planejamento de } \\
\text { médio prazo }\end{array}$ \\
\hline
\end{tabular}

\section{Conclusões}

Identificou-se que a implementação das diretrizes propostas possui uma maior aplicabilidade em ambientes do tipo ETO, por possuírem situações de simultaneidade entre as etapa de projeto e de produção, bem como por estes ambientes estarem sujeitos a uma alta variação das demandas de mercado ao longo do tempo, necessitando assim estabelecer fluxos contínuos na IPPP. Ademais, torna-se fundamental um estudo mais aprofundado em que sejam aplicadas as diretrizes propostas em uma empresa do setor.

1- MITCHELL et al. A conceptual framework of the interface between the design and construction processes. Engineering, Construction and Architectural Management, v. 18, n. 3, p. 297-311,2011.

2- ARROTÉIA, A. V. Gestão do projeto e sua interface com o canteiro de obras sob a ótica da preparação da execução de obras (PEO). 2013. Dissertação de Mestrado - Curso de pós-graduação em Engenharia Civil, Universidade Federal de Goiás, Goiânia. 